\title{
Learning to Learn: Defining an Engineering Learning Culture
}

\author{
Marnie Vegessi Jamieson and John M. Shaw \\ Department of Chemical and Materials Engineering, Faculty of Engineering, University of Alberta \\ mvjamies@ualberta.ca and jmshaw@ualberta.ca
}

\begin{abstract}
Learning is a cultural construct. Beliefs, perceptions and values regarding learning shape the culture of a classroom and a program of study. A framework for engineering education grounded in the Canadian Engineering Accreditation Board (CEAB) Graduate Attributes and engineering practice is proposed. Methods and activities to shape a learning culture in engineering design education consistent with a community of practice and lifelong learning are also proposed. This transformational approach offers an opportunity to teach lifelong learning and integrate engineering practice and engineering education, while entrenching graduate attributes more deeply in the engineering curriculum. Accountability, engagement, recognition, motivation, appreciation, credibility, and continual improvement are key elements of a functional learning culture. Learning moments are a concise way to make learning to learn a relevant part of each session and encourage student reflection and metacognition.
\end{abstract}

Keywords: Community of Practice, Graduate Attributes, Design, Capstone, Student, Self, Outcomes, Course, Life Long, Learning, Culture, Competency-based, Metacognition, Engagement, Motivation, Reflection, Learning Moments, Engineering Education Framework

\section{INTRODUCTION}

This contribution describes the definition and development of a learning culture framework, its foundation in the literature, and its application to engineering design education. To define a learning culture we examine conceptions and beliefs regarding learning, teaching, community, intelligence, motivation, accountability, innovation, and learning culture design.

A learning culture is developed in an engineering program of studies as a result of interactions between learners, teachers, system designers, and administrators. In this work we investigate the underlying philosophical orientations and themes of a learning culture relevant to graduate attribute development. This work attempts to answer several questions related to the interaction of engineering education with the graduate attributes. The initial presumptions are outlined below.

What defines a learning culture? Beliefs, perceptions, and values regarding learning and intelligence underlie the preparation of course materials and the ensuing student approaches to learning [1,10,11,12,24,29,55,58]. The learning framework and philosophical orientation we choose to inform learning activity design whether behaviorist (empiricist), cognitive (constructivist/ rationalist), or situative (pragmatist/functionalist) [31,57], has defining elements rooted in differing philosophical perspectives (Appendix A). These perspectives can be utilized in a complementary fashion to achieve a variety of learning outcomes [31,68] using critical realism [7] and metacognitive teaching strategies [26] to support outcomes-based engineering education $[36,45,46,49,50,58]$ and continual improvement $[44,46]$.

What characteristics are required to be an engineer? The twelve CEAB outcome-based performance criteria, referred to as graduate attributes [14], include fundamental knowledge, comprehension, analysis, socio-contextual, metacognitive, and professional practice outcomes $[13,55,56,65,66]$. The CEAB graduate attributes are based on international agreements distinguishing characteristics of engineering work from technologist and technician work [36,37]. Outcomes-based assessment criteria can be conceptualized as holistic and context-dependent combinations of knowledge, skills, and attitudes [35,56]. An engineering identity is grounded in an engineering program including design and project-based learning experiences $[14,36,37]$ aimed at integrating fundamental and complementary knowledge with metacognition in a professional community of practice.

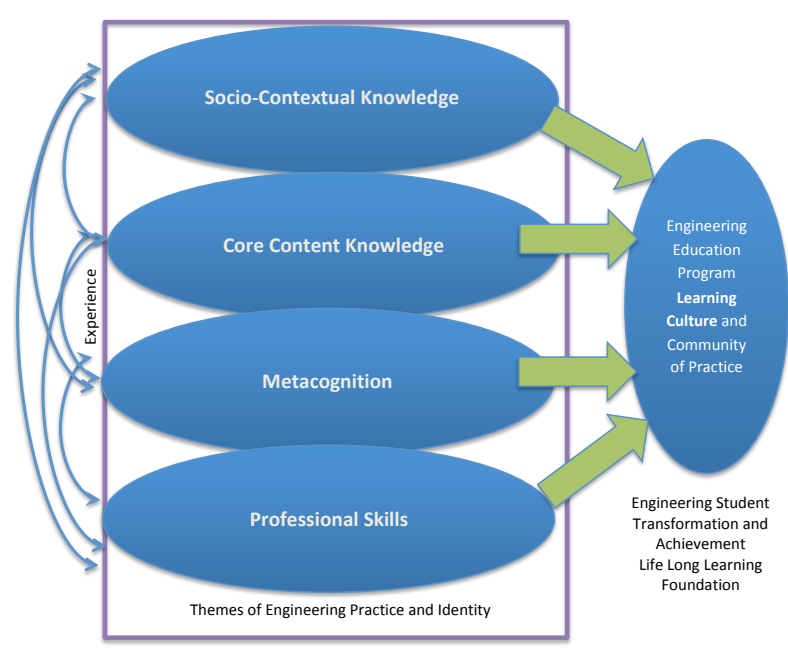

Figure 1. Proposed Engineering Education and Practice Theoretical Framework 
What defines an engineering learning culture? A theoretical framework identifies the major themes of a phenomenon of interest. The supporting conceptual framework is a network of linked concepts [35]. The CEAB graduate attribute performance outcome measurement and the phenomena of their application to a continual improvement process [14] for engineering education presuppose ontological (related to the nature of reality and existence) and epistemological (related to the nature of knowledge and systems) assumptions or beliefs. A thematic analysis of graduate attribute prepost process design course student self-assessment constructs [46] accompanied by extensive reading, and categorization of graduate attribute related literature and discourse produced four core engineering education themes: core content knowledge, socio-contextual knowledge, professional skills, and metacognitive skills. These core graduate attribute themes inform a proposed theoretical framework (Figure 1) that may be employed for engineering education learning culture development and continual improvement processes $[41,44]$. The CEAB graduate attributes along with their history, mapping, implementation, implications for engineering practice and identity inform the conceptual framework (Figure 2) elaborated in this contribution. The proposed conceptual framework was developed using a multistep conceptual framework analysis process [39] presented in Appendix B. The penultimate step of the process is the presentation of the proposed framework to scholars and practitioners for validation, a key objective of this work.

We propose using the theoretical framework presented in Figure 1, for positive learning culture development in engineering education and for fostering an emerging professional engineering identity, in students, as anticipated by CEAB graduate attribute attainment levels at the end of an engineering program.

\subsection{Literature Review}

Engineering work is complex [16] and is typically a response to a societal need. Engineering education can also be described as complex and a response to societal needs. This complexity includes the development of a transferable learning culture [34]. A learning culture is developed regardless of whether we pay attention to its development. Elements of a positive learning culture include accountability behaviours, self-regulation, engagement with cognitive tasks, appropriate level of task difficulty, community, motivation for learning, recognition of achievement, appreciation of effort, and credibility. We explore this complexity in the literature.

1.1.1 Learning and Teaching. Student development and learning can be enhanced with metacognitive strategies, feedback, engagement, spaced practice [35], contextual content, and realistic practice [34]. Including these strategies in a program of study and deliberately teaching learning behaviors, concepts, and strategies assists students to develop the technical, contextual, metacognitive [26,68], and professional skills required to achieve the CEAB graduate attribute performance outcomes, and supports the emergence of a positive learning culture foundational to life-long learning $[2,12,18,29,34,36,55,58,71]$. "Teachers who consider their students' self-efficacy beliefs, goal setting, strategy use, and other forms of self-regulation in their instructional plans not only enhance students' academic knowledge, but they also increase their students' capability for self-directed learning throughout their life span." [71, p.35] Human learning and self-regulation are a complex interplay between behavioral, cognitive/ affective, and environmental/social factors [71].

Behaviorist learning theories have evolved toward neural network knowledge models [31], and support retrieval and organization of knowledge in response to stimuli. Content tends to be hierarchical and progressive from simple to complex. Cognitive learning theories $[31,36,48]$ support student knowledge acquisition as concepts and knowledge development processes in active learning environments [26,30,36,48,57]. Students who develop self-conscious management of the learning process (metacognition) often perform better than those who do not $[8,9,13,31,36,50]$. Situative or functional (contextual) learning theories including student discourse related activities such as collaborative learning, leadership, task planning, and work strategies combined with iterative design processes can lead to metacognitive regulation and a recursive learning cycle $[20,23,35,54,52,58]$. Reflection during learning cycles leads to targeted practice that further develops technical, design, team, and leadership skills that transfer to new circumstances $[2,11,12,36,46]$. A community of practice is inherently a situative learning environment since it requires participation in relevant discourse on discipline knowledge, concepts, and applications [29,30,31,46]. These learning orientations reflect differing perspectives on the nature of knowledge, learning, and motivation, but all address knowledge aggregation - from individual to societal and from simple to complex.

1.1.2 Failure and Intelligence. Instructor responses to student successes, struggles, and failures impact student outcomes [24,58,61]. Valuing effort and failure associated with the learning process can result in the development of a growth mindset associated with student achievement and success [24,33,58,61]. Strategy-based instructor feedback on student performance can positively impact student motivation and investment in learning while feedback intended to comfort following a struggle or failure does not [61]. In addition, student beliefs about intelligence as an entity theory construct (fixed mindset) is related to their overconfidence level and a preference for ease in 
learning activities while an incremental theory construct (growth mindset) is related to a more accurate estimation of abilities (greater self-insight), and a tendency to attempt more challenging problems [25]. Student and instructor beliefs about intelligence, effort and strategy can change when presented with new conceptions and evidence to consider [24,25,33,58,61].

1.1.3 Motivation and Accountability. Life-long learning is characterized by initiative, independence, self-discipline, curiosity, confidence and persistence in learning; accepting responsibility for learning; viewing problems as challenges not obstacles; use of basic study skills, time management, pacing, task planning, goal setting, and learning enjoyment $[32,58,59]$. Guglielmino [32] characterizes life-long learning as a collection of values, beliefs, behaviors, and perceptions about learning and personal efficacy when learning. "Lifelong learning may operate as a critical resilience factor that combats fatigue and exhaustion associated with the ongoing demands and challenges..." [59, p.128].

1.1.4 Innovation. Innovation processes $[46,63]$ and effectuation thinking $[63,64]$ can be employed in design courses. Contextual learning of this nature is described as strengthening the practices of the community [31, 55]. To be effective learners must be offered legitimate peripheral participation [34,55]. Innovation requires thinking processes, goal setting [60], and strategies $[21,36,51,63,64]$ including effectuation thinking $[63,64]$. Effectuation describes a thinking process used when there is uncertainty and imagined solutions must be developed from available means within constraints. The practice of innovation requires an environment where development of imagined ends is necessary [21,51]. Learning innovation requires legitimate participation in a community of practice where innovation is valued. Student participation in a community of practice affords opportunities for development of innovation, leadership, and professional capabilities $[41,48]$.

1.1.5 Learning Culture Design. Online and blended learning environments have highlighted the importance of the social and community aspects of learning. An online learning community of inquiry requires social, cognitive, and teaching presences to be effective [30]. This necessitates student cognitive engagement with content, engaged social behaviors, and learning goals [60] in the context of the discipline standards and the communication media. These elements describing an online learning culture are found in face to face, blended $[27,28,47,69]$, and corporate based learning cultures $[1,22,70]$. They are essential elements of mentorship [67], lifelong learning practices $[2,58,67]$ and preindustrialization communities of practice [22]. "Social cognitive theory assumptions address the reciprocal interactions among persons, behaviors, and environments; enactive and vicarious learning (i.e., how learning occurs); the distinction between learning and performance; and the role of self-regulation" [67, p.119]. An evidence based learning culture supporting graduate attribute outcomes recognizes learning for individual students is unique and common. Learning precedes performance. Strategies for learning (and teaching) can be examined and chosen depending on the nature of the graduate attribute performance outcome. A learning culture leverages a contextual community of practice, innovation opportunities, growth mindsets and life long learning characteristics. It encompasses multiple learning perspectives, engagement dimensions, and the values rooted in the graduate attribute outcomes and emerging professional engineering identities.

\subsection{Philosophical Framework}

Critical Realism [7] allows for individual subjective human interpretation of an objective independent reality or existence [15]. Critical realism separates ontology (views of the nature of reality and existence) from epistemology (views of the nature of knowledge and systems) [17]. The cultural, moral, technological, economic, environmental, and safety realities of individuals along with human beliefs have evolved over time. "Students, instructors, and engineers are all a part of society and experience this reality from their own perspective" [41, p.5].

The phenomena studied may influence our ontological perspective. Phenomena can be complicated or complex [16]. A complicated phenomenon is one where an outcome can be reliably predicted using the past behaviour of the system, mathematical modeling and prediction [16]. A complex phenomenon is one where the outcome is not easily predicted. There are many interacting variables and outcomes are not easily or reliably measured and modeled mathematically [16]. Our ontological framework is Complex Critical Realism (CCR) [15]. Our epistemological framework is situative (knowledge is contextual) and depending on the research question, qualitative, quantitative, or mixed methods may be required [19] (Appendix A).

A learning culture is rooted in CCR. More than just a pragmatic view of using "whatever works" for an individual to achieve the learning outcomes; complex critical realism expects different perspectives (behaviourist, cognitive, and situative) in a complex system. The learning tools associated with theories that describe part of the whole can be combined in an emergent learning environment that is the sum of the parts. Learning tools are selected by learners and teachers depending on the task at hand to achieve the common goal of graduate attribute outcome achievement during a course or a program of study [41]. 


\subsection{Problem Definition and Motivation}

The rapidly changing work of engineers [53] creates additional tension between historical engineering education paradigms and the requirements for practicing engineering now and in the near future. The continual improvement process and focus on graduate attribute development will have an ongoing impact on our learning culture. Developing the capacity for life-long learning and the ability to integrate it into a sustainable learning culture is the key motivation for this work. Our ongoing continual improvement process $[38,40,41,44]$ initially focused on the capstone process design course was then extended to the process design course sequence and now to collaboration with administrators and other instructors to achieve program and cultural improvements.

\subsection{Solutions Explored}

The capstone process design course instructors participated in an ongoing university wide digital learning initiative. The objectives of the instructors were to enhance the interactions between instructors and student design teams [49] and to align the course strategically with the graduate attributes [14]. A blended-learning project-based course structure was designed and implemented using aligned course objectives, learning activities, and performance based assessment. The course was evaluated and compared to the traditional delivery iterations $[40,45]$. A continual improvement process [40,41] grounded in the performance attribute work of Hattie [35] and the constructive alignment work of Biggs [6] was recommended, as were specific continual improvement interventions [40,42-50]. Further work led to the identification and enhancement of the metacognitive structure of the capstone chemical process design course as three successive cycles built around design project phases and milestones (Figure 3) [42,43], and a course based continual improvement process linked to the program level continual improvement process $[38,41]$.

In this work, we explore the application of the proposed engineering education theoretical and conceptual frameworks (Figures 1 and 2) to learning culture development, graduate attribute achievement support, and a transferable learning orientation $[1,18,34,62]$. The adoption of complex critical realism as a philosophical framework allows for combined learning perspectives and tools to further support an effective graduate attribute informed learning culture (Appendix A). CCR encourages instructors to examine the impact of their own experiences, beliefs, perceptions, and values on their teaching. Industrial and practicing engineers allied with a design teaching team form a community of practice where committed practicing engineers contribute projects and participate in innovation and learning processes with students. This engagement provides an explicit learning space for discipline specific discourse and supports an incremental theory of intelligence by providing models of life long learners. Learning Moments, patterned like safety moments used to develop safety culture in industry, are proposed to enhance ongoing student engagement with metacognition, learning behaviors, cognitive strategies, and contextual practice.

\subsection{Significance}

Student and instructor feedback combined with writing assignments has provided qualitative data and is used along with quantitative assessment data for course evaluation and identifying improvement actions then used as input for the program level continual improvement process [41]. This process integrated with the application of the proposed theoretical and conceptual frameworks has led to the development of a learning culture supported by a discipline relevant community of practice. Students are engaged, motivated, and appear to enjoy design [47]. The learning culture established persists from year to year due to support from a stable design teaching team, community of practice, and inter-cohort peer to peer interactions.

\subsection{DEFINING A LEARNING CULTURE}

Undergraduate engineering curricula should provide opportunities for students to learn, practice, and demonstrate development of CEAB graduate attributes, to reflect on progress and then target next steps to continue learning. A learning culture supports this goal. Identifying the key elements of an undergraduate engineering learning culture and encouraging its growth improves the quality of undergraduate engineering education. Evidence based elements of our learning culture include: recognizing achievement and rewarding learning behaviors; engagement with cognitive and metacognitive development; growth mindset oriented feedback to encourage effort and to initiate strategies for improvement; contextual innovation and design processes with relevant contextual problems embedded in a community of practice. These elements embrace the behavioral, cognitive, contextual, and practice dimensions of learning and the learning required to be an engineer.

Learning moments and learning objectives presented at the start of each lecture or tutorial keep learning a priority. Frequent formative assessments with generous feedback leading up to summative assessments encourage learning behaviors. The construction of learning activities by students in an environment where the learning objectives of a program of study are consistent with the required assessments and outcomes 
are central to the theory of constructive alignment $[6,27,31,35,67]$ and to cognitive course design. Learning about learning and reflective strategies $[20,21,65,66,71]$ introduces students to and teaches them about metacognition, teamwork, design, and innovation processes [34,35,40,48,52,57,58]. A blended and active learning environment engages students in engineering work processes and encourages reflection and sense making $[27,35,40]$. Ongoing formative feedback and self-assessment are inputs to a growth mindset [58] and life long learning [2,34]. A formal community of practice provides mentors and models of the engineering design and innovation process for students in a learning environment intended to give contextual practice of innovation, leadership, professional, and project management skills [42,48].

\subsection{METHOD}

Three related qualitative data analysis studies were undertaken to identify essential learning theory elements for a future relevant, graduate attribute achievement driven, and continually improving chemical engineering design course based learning culture. The overall intent of Study 1 is to develop the theoretical and conceptual frameworks (Figures 1 and 2) relating graduate attribute outcome achievement to the learning and development processes. The overall intent of Studies 2 and 3 is to identify key features in a learning culture informed by the CEAB graduate attributes (Appendix C), by examining the learning frameworks and conditions required to achieve the outcomes suggested by the graduate attributes.

\subsection{Study 1: Conceptual Framework Analysis}

Here we investigated emerging common themes for the application of the graduate attributes to an engineering education continual improvement process. The scope of work included an analysis of the skills required for successful student teams in chemical process design using a multi-step conceptual framework analysis process (Appendix B).

In the first step, documents related to the history and development of the CEAB graduate attributes, performance outcome-based education, online and blended learning delivery, learning theories, motivation, intelligence, design, innovation, metacognition and reflection, engineering practice and leadership, lifelong learning, qualitative and quantitative research methods, continual improvement, and learning culture were identified. The second step comprised "reading for a multidisciplinary perspective" and included engineering accreditation and work descriptions [14,36,37,52,53], education, learning, innovation, metacognitive and lifelong learning literatures. The results of this step are outlined in our literature review and presented as a graphical summary of the philosophical, epistemic, learning theory, and delivery framework relationships in Appendix A. The next two steps comprised contextual and conceptual analysis of pre-post course student skill self-assessment constructs. The same process was applied to selected documents including the CEAB graduate attribute descriptions, graduate attribute accreditation evaluation procedures [14], International Engineering Alliance documents related to the Washington Accord [36,37], and our existing practices. During the fifth step, key themes describing engineering education were identified. These resulted in the theoretical framework presented in Figure 1. The conceptual network (Figure 2) and the metacognitive course structure (Figure 3 ) are outcomes of step six.

The current and seventh step is validation of the proposed theoretical and conceptual frameworks shown in Figures 1 and 2. This step has been in progress for twelve months and includes feedback from presentations at two conferences and personal communications.

\subsection{Study 2: Graduate Attribute Outcome Learning Framework Categorization Coding}

Here we categorized the CEAB graduate attributes using behaviorist (empiricist), cognitive (rationalist), or situative/contextual (pragmatic/functionalism) tags, and studied the philosophical underpinnings of the graduate attributes, the design course, and our developing learning culture. The purpose of study 2 was to examine the graduate attribute outcomes and determine the perspective that might be required to teach and learn how to demonstrate graduate attribute attainment achievement.

\subsection{Study 3: Metacognitive Structure Mapping}

Here we mapped the course cognitive and metacognitive structure. We considered impacts of time progression, social cognitive interactions including the community of practice and course milestones.

\subsection{RESULTS AND DISCUSSION}

In this work and for the purpose of validating the framework a brief summary of the results is included.

\subsection{Study 1: Conceptual Framework Analysis}

A team selection tool requires the capstone design teams to collectively identify their team skills and have a plan to address their collective weaknesses. Although the intent of the tool has been consistent historically, during the 2014 blended course redevelopment the activity was moved online and later integrated into the introductory design course. As a result of previous graduate attribute mapping, the identified skills are 
categorized using the CEAB graduate attributes. The pre and post course self-assessment activities measure student perceptions of their development with respect to the attributes. Irrespective of the ongoing activity development and continual improvements applied, the skills have remained consistent and describe skills teams need to complete their process design projects successfully $[40,46]$. The graduate attribute categories were analyzed for common themes using the skill constructs and the graduate attribute descriptions. Four themes emerged from the analysis of the two key data sources. Documents listed in the references were used to provide further categorical evidence. The skills were sorted into four themes to produce the conceptual framework presented in Figure 2.

\subsection{Study 2: Graduate Attribute Outcome Learning Framework Categorization Coding}

A qualitative textual analysis of the twelve CEAB Graduate Attributes with respect to the categorization of the behavioral, cognitive, and contextual response expected by the graduate attribute outcome descriptions is summarized in Table 1. The tagged classifications are presented in Appendix C. An item was tagged as behavior if the primary response is a behaviorist expectation and/or a response to a stimulus (if condition then expected action); items were tagged as cognitive if the primary response was a cognitive expectation and or related to constructing meaning; items were tagged as situative if the response was classified as primarily contextual and/or was likely to require multiple integrated perspectives to develop a response. Cognitive task descriptions in the graduate attributes such as analyze, synthesize, evaluate, create were typically tagged as cognitive and descriptors such as understand, demonstrate, were tagged as behaviorist as a response to a stimulus appears to be expected. If an item could be categorized more than once, a forced choice was made with a bias to the category that was not already noted for a specific graduate attribute.

The coding for: "9. Impact of engineering on society and the environment" provides an illustrative example. "An ability to analyze" is tagged as a cognitive response as it suggests constructing meaning. An ability to construct an analysis of possible or actual impacts and rate or classify impacts whether quantitatively or semi-quantitatively and according to degree of impact relative to ranking criteria. The remainder of the phrase "social and environmental aspects of engineering activities, " is tagged as situative because it requires a contextual response or evaluation of the quantitative and qualitative data required for the analysis content and context. "Such ability includes an understanding of interactions that engineering has". Understanding is a response to a stimulus (a requirement to understand) and is coded as behaviorist. Engineering interactions with... is coded as cognitive as it suggests

\begin{tabular}{|c|c|c|c|}
\hline Attribute & Behaviorist & Cognitive & Situative \\
\hline 1 & 1 & 4 & 2 \\
\hline 2 & 2 & 4 & 2 \\
\hline 3 & 1 & 5 & 1 \\
\hline 4 & 1 & 5 & 7 \\
\hline 5 & 3 & 2 & 2 \\
\hline 6 & 1 & 1 & 1 \\
\hline 7 & 3 & 2 & 7 \\
\hline 8 & 4 & 1 & 1 \\
\hline 9 & 4 & 4 & 5 \\
\hline 10 & 1 & 1 & 1 \\
\hline 11 & 1 & 3 & 3 \\
\hline 12 & 1 & 4 & 1 \\
\hline
\end{tabular}

cognitive analysis and sorting. "[W]ith the economic, social, health, safety, legal, and cultural aspects of society," is contextual and is coded as situative. "[T]he uncertainties in the prediction of..." is coded as cognitive for the conceptual relationship uncertainty analysis underlying the extension to the use and integration of the contextual information which is coded as situative. "[S] uch interactions and the concepts of sustainable design and development and environmental stewardship were coded as a response to accountability requirements, and thus behaviorist. Concepts was coded cognitively and interactions was coded as situative. Aspects of all three elements could be seen in this text. Elements of all three learning theory perspectives were found in each graduate attribute.

\subsection{Study 3: Metacognitive Structure Mapping}

This study addressed the time structure and progression of student development and their design projects in the introductory and capstone process design courses. The structure of the milestone learning actives was found to comprise three metacognitive cycles per course that roughly span 4 -week periods. The cycles, illustrated in Figure 3, are characterized by formal interactions within the community of practice, the cognitive and behavioral requirements of the course to produce project milestone requirements, and the final products (reports, posters, presentations). Academic advisors and the student teams manage the behaviorist aspects of the cycles. Both design courses require initial reflection on individual and team personal development then further plan, monitor, and reflect cycles progress the design teamwork and the course toward completion. 


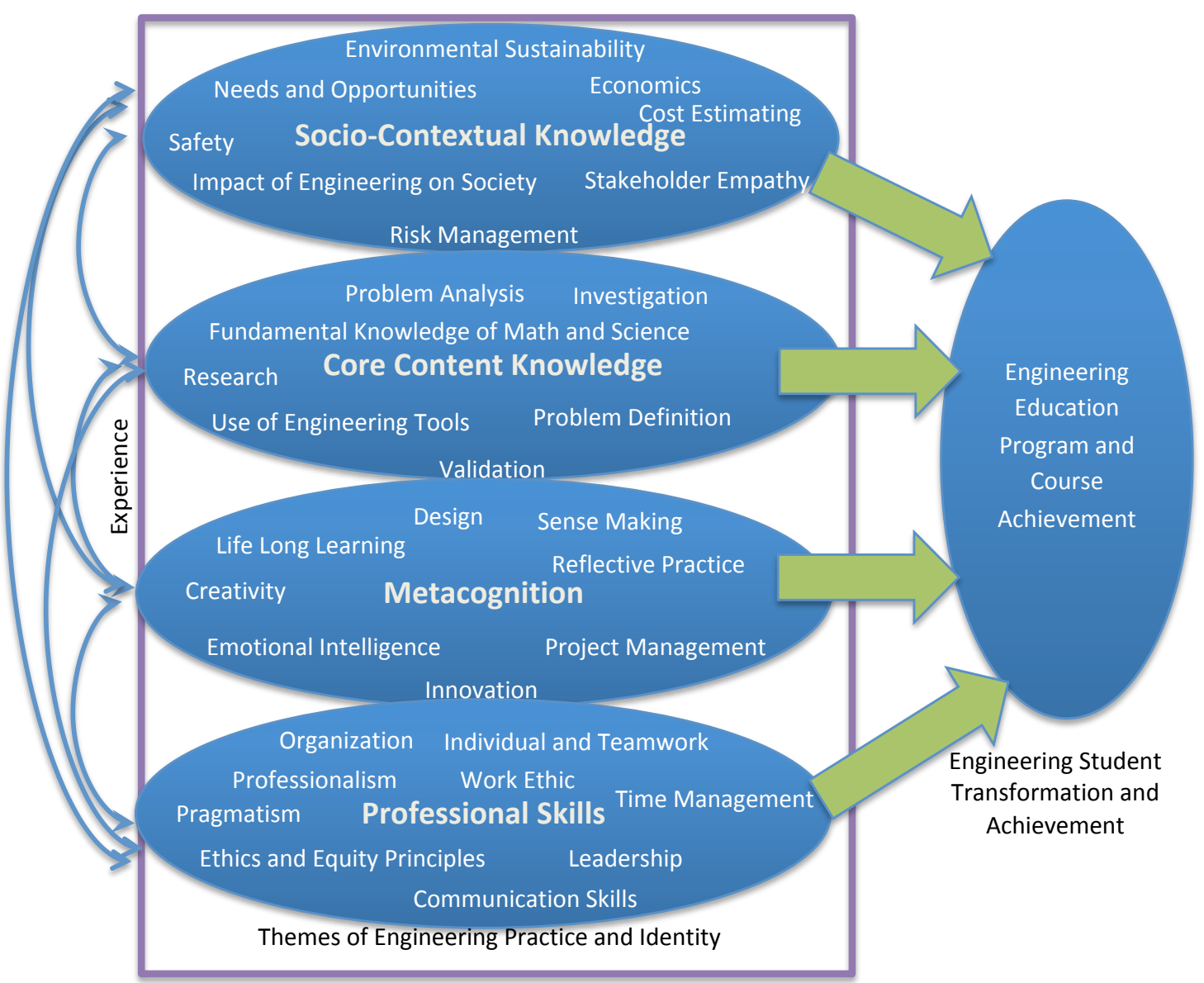

Figure 2. Proposed Engineering Education and Practice Conceptual Framework

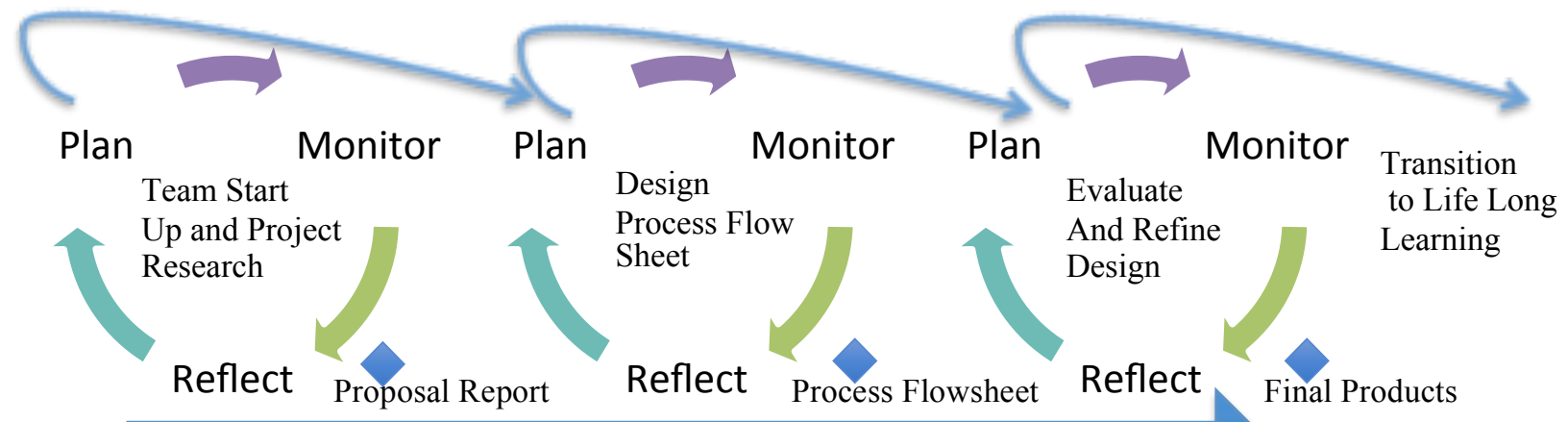
Design Project Development and Team Competence

Figure 3. Design Course Metacognitive Cycles Progressing Team and Project Development CASEE 2018 paper by authors reproduced according to guidelines. 


\subsection{CONCLUSIONS}

The CEAB graduate attributes appear to describe an emerging professional identity and along with a continual improvement process determine the required characteristics of an undergraduate learning culture. The engineering education and practice framework was developed, in part, by the examination of the skills design instructors have historically observed to underlie student team success in the capstone process design course and more recently associated with successful graduate attribute achievement. The proposed theoretical framework was used to further develop the learning culture in the chemical process design sequence including metacognitive skill development activities. The theoretical framework consists of four themes: core content, socio-contextual content, metacognitive and professional skills. This theoretical framework is proposed along with the supporting conceptual framework as a basis for the creation of an engineering education learning culture informed by the CEAB graduate attribute outcomes.

Further examination of the graduate attributes in the context of learning frameworks indicates elements of behaviorist, cognitive, and situative learning constructs. It would appear the CEAB graduate attributes are conceptualized as holistic and context-dependent combinations of knowledge, skills and attitudes requiring a mixed learning theory framework to support development. An examination of the learning activities and learning culture created in the process design courses also demonstrates elements of a mixed learning theory framework. This is consistent with the adoption of complex critical realism as a philosophical perspective for engineering design education and the complimentary use of a variety of learning perspectives to achieve the complex CEAB graduate attribute performance outcomes.

\section{Acknowledgements}

The design course redevelopment was funded by the Provost's Office (University of Alberta). The CTL blended learning research project, of which this research is a part, received research ethics approval from the University of Alberta Research Ethics Board, No. Pro00048272. The authors acknowledge with thanks the support given by our community of practice - our students, our teaching team, our research community, and our industry participants. A special thank you to Michel Perrier, Sylvie Doré, Norma Nocente, and John Nychka for their helpful review and comments.

\section{REFERENCES}

[1] Annie Aarup, Jensen, Xiangyun Du, and Mikkel Kirkebæk. Teaching and Learning Culture: Negotiating the Context. Rotterdam: Sense Publishers, 2013.
[2] Richard J. Aleong, \& David S. Strong, "The Development of LifeLong Learning Competencies: Positioning Students for Selfregulation,” Proc. CEEA15, 158, McMaster; May 31 - June 5, 2015.

[3] M. Archer, C. Decoteau, P. Gorski, D. Little, D. Porpora, T. Rutzou, C. Smith, G. Steinmetz, \& F. Vandenberghe, "What is Critical Realism?" Perspectives, 38(2), pp. 4-9, 2016.

[4] Ken Bain, What the Best College Teachers Do. Cambridge, Mass.: Harvard University Press, 2004.

[5] John C. Bean, Engaging Ideas: The Professor's Guide to Integrating Writing, Critical Thinking, and Active Learning in the Classroom. $2^{\text {nd }}$ ed. Jossey Bass : San Francisco, 360 p. 2011.

[6] John Biggs, What the student does: teaching for enhanced learning, Higher Education and Development 18(1):57-75, 1999.

[7] Roy Bhaskar, A realist theory of science. London: Verso, 1975.

[8] Monique Boekaerts, "Self-regulated learning at the junction of cognition and motivation," European Psychologist, 1, 100-112, 1996.

[9] M. Boekaerts \& L. Corno, "Self-regulation in the classroom: A perspective on assessment and intervention," Applied Psychology: An International Review, 54, 199-231, 2005.

[10] Liliya S. Bormotova, "A Qualitative Study of Metacognitive Reflection: The Beliefs, Attitudes and Reflective Practices of Developing Professional Educators," Theses and Dissertations, http://knowledge.library.iup.edu/etd/434, 2011.

[11] David Boud, Ruth Keogh, \& David Walker (Eds), "Using experience for learning," Society for Research into Higher Education University Press: University of Michigan, 1993.

[12] David Boud, Ruth Keogh, \& David Walker (Eds), Reflection: Turning experience into learning, Psychology Press, 1985.

[13] A. Brown, (1987.) Metacognition, executive control, self control, and other mysterious mechanisms, in F. Weinert \& R. Kluwe (Eds.), Metacognition, motivation and understanding, pp. 65-116. Hillsdale, NJ: Erlbaum.

[14] Canadian Engineering Accreditation Board, "Canadian Engineering Accreditation Board: Accreditation Criteria and Procedures", Ottawa: Can. Council of Prof. Engineers, 2014. Accessed June 20, 2015.

[15] Alex M. Clark, S.L. Lissel, C. Davis, (2008). Complex Critical Realism: Tenets and Application in Nursing Research Advances in Nursing Science, 31(4), pp. E67-E79.

[16] Alex M. Clark, T.G. Briffa, L. Thirsk, L. Neubeck, J. Redfern, What football teaches us about complex health interventions BMJ: British Medical Journal, 345 (7888), pp. 25-27, (2012). [Accessed: 22-062018] Published by: BMJ URL: http://www.jstor.org/stable/23493387

[17] Centre for Critical Realism (CCR) (2016). "Roy Bhaskar Transcendental Realism" About Critical Realism CCR Blog at WordPress.com Website established 1997 [Accessed: 22-06-2018]

[18] Marcia L. Conner, and James G. Clawson. Creating a Learning Culture : Strategy, Technology, and Practice. Cambridge : Cambridge University Press, 2004.

[19] John W. Creswell, A concise introduction to mixed methods research. Sage Publications, 2015.

[20] John Dewey, How we think: A restatement of the relation of reflective thinking to the education process. Boston: Houghton Mifflin, 1998

[21] Peter Drucker, The Discipline of Innovation, Harvard Business Review, 1985.

[22] Emile Durkheim, The Division of Labor in Society. New York: Free Press, 1964.

[23] S.J. Durning, \& A.R. Artino, "Situativity theory: A perspective on how participants and the environment can interact": AMEE Guide no. 52. Medical Teacher, 33(3), pp. 188-199, 2011.

[24] Carol S. Dweck, "Self-theories: Their role in motivation, personality and development," Taylor Francis Psych. Press, Philadelphia, 1999.

[25] Joyce Ehrlinger, Ainsley L. Mitchum, Carol S. Dweck, "Understanding overconfidence: Theories of intelligence, preferential attention, and distorted self-assessment," Journal of Experimental Psychology, 63(2016), 94-100, Elsevier, 2016.

[26] Greg J. Evans "A windmills of your mind: metacognition and life long learning," Proc. 2018 Canadian Engineering Education Conference (CEEA18), Paper 38, Vancouver, BC; 3-6 June 2018. 
[27] D. Randy Garrison and Norman D. Vaughan, Blended Learning in Higher Education: Framework in Principles, and Guidelines. San Francisco, CA: Jossey-Bass, 2008, 272 pp.

[28] D. Randy Garrison, Terry Anderson, \& Walter Archer, "Critical inquiry in a text-based environment: Computer conferencing in higher education," The Internet and Higher Education, 2(2-3), 87-105, 2000.

[29] D. Randy Garrison, \& J.B. Arbaugh, "Researching the community of inquiry framework: Review, issues, and future directions," The Internet and Higher Education, 10(2007), 157-172 2007.

[30] D. Randy Garrison, \& Marti Cleveland-Innes, Facilitating cognitive presence in online learning: Interaction is not enough. American Journal of Distance Education, 19(3), 133-148, 2005.

[31] J. Greeno, A. Collins, \& L. Resnick, Cognition and Learning. In R. Calfee \& D. Berliner (Eds.), Handbook of educational psychology (pp. 15-46). New York, NY: MacMillan, 1996.

[32] L.M. Guglielmino, Development of the self-directed learning readiness scale. Doctoral dissertation, University of Georgia, 1977.

[33] Kyla Haimovitz, and Carol S. Dweck. 2017. "The Origins of Children's Growth and Fixed Mindsets: New Research and a New Proposal." Child Development 88 (6): 1849-59.

[34] M. Henton, Adventure in the Classroom: Using Adventure to Strengthen Learning and Build a Community of Life-long Learners, Dubuque Iowa: Kendall/Hunt, 1996.

[35] John Hattie, "The Black Box of Tertiary Assessment: An Impending Revolution". in L. H. Meyer, S. Davidson, H. Anderson, R. Fletcher, P.M. Johnston, \& M. Rees (Eds.), Tertiary Assessment \& Higher Education Student Outcomes: Policy, Practice \& Research (pp.259275). Wellington, New Zealand: Ako Aotearoa, 2009.

[36] International Engineering Alliance (IEA), Graduate Attributes and Professional Competencies, 2013. IEA. http://www.ieagreements.org/

[37] International Engineering Alliance (IEA), Best Practice in Accreditation of Engineering Programs: an Exemplar, 2015. IEA.

[38] Marcus Ivey, S. Dew, M. Mandal, Y. Mohamed, J. A. Nychka, D. Raboud, J.P. Carey, "Using post course assessments to involve instructors in the continuous improvement process," Proc. CEEA2017, G. Evans (ed) (Toronto, Ontario; 4-7 June 2017), Paper 041.

[39] Yosef Jabareen, "Building a Conceptual Framework: Philosophy, Definitions, and Procedure.” Inter. Jour. of Qual. Meth., 2009, 49-62.

[40] Marnie V. Jamieson, "Application of blended and active learning to chemical engineering design instruction”, University of Alberta, 2016.

[41] Marnie V. Jamieson and John M. Shaw, "A continual improvement process for teaching leadership and innovation within a community of practice," Proceedings of The American Society for Engineering Education Conference, (ASEE19), Tampa, Florida; 16-19 June 2019.

[42] Marnie V. Jamieson and John M. Shaw, "Applying metacognitive strategies to teaching engineering innovation, design, and leadership," in Proc. 2017 Canadian Engineering Education Conf. (CEEA17), G. Evans (ed), Toronto, ON; 4-7 June 2017), Paper 045

[43] Marnie V. Jamieson and John M. Shaw, "CATME vs. ITP Metrics Which one should I choose?" Proceedings of (ASEE18), Salt Lake City, Utah; 24-27 June 2018.

[44] Marnie V. Jamieson and John M. Shaw, "Graduate attribute based continuous improvement ...- a writing seminar case study," in Proc. (CEEA18), Paper 77 P. Ostafichuk (ed) Van., BC; 3-6 June 2018

[45] Marnie V. Jamieson and John M. Shaw, "Online learning element design - development and application experiences", Proc. (CEEA16), Paper 038, Dalhousie University; June 19-22, 2016.

[46] Marnie V. Jamieson and John M. Shaw, "Pre and Post Course students self assessment of CEAB Graduate Attributes - A Tool for ...Course Improvement," Proc. (CEEA16) Paper 037 Dal., 2016.

[47] Marnie V. Jamieson and John M. Shaw, "Student and Instructor Satisfaction and Engagement with Blended Learning in Chemical Engineering Design", in Proc. (CEEA17) Paper 040; U of T, 2017

[48] Marnie V. Jamieson and John M. Shaw, "Teaching Engineering Innovation, Design, and Leadership within a Community of Practice," Proc. 2018 Canadian Engineering Education Conference (CEEA18), Paper 113, P. Ostafichuk (ed) Vancouver, BC; 3-6 June 2018.

[49] Marnie V. Jamieson, Len Church, Frank Vagi, William Pick, Tracy Onuczko, John Nychka, Norma Nocente and John M. Shaw, "The
University of Alberta Chemical Engineering Capstone design Course Goes Flipped!" in Proc. (CEEA15) Paper 93, McMaster University; May 31 - June 3, 2015.

[50] Marnie V. Jamieson, Leah Goettler, Albert Liu, and John M. Shaw, "To Teach is to Learn: Student and Instructor Perspectives on Assignment Development as a Springboard to Deep Learning," in Proc. of the 13th CDIO Conf., Calgary, Canada, 18-22, June, 2017

[51] Steve Johnson, Where Good Ideas Come From: The Natural History of Innovation, Riverhead Trade, 2011.

[52] Aditya Johri \& Barbara M. Olds, Situated Engineering Learning: Bridging Engineering Education Research and the Learning Sciences. Journal of Engineering Education, 100(1), 151-185 2011.

[53] Joyner, F.F., Mann, D.T.Y., Harris, T. (2012). Engineering as a social activity: Preparing engineers to thrive in the changing world of work. American Journal of Engineering Education, 3(1), 67-81.

[54] Alice Y. Kolb \& David A. Kolb, "The Learning Way: Metacognitive Aspects of Experiential Learning," Simulation \& Gaming, 40(3), 297-327 2009.

[55] J. Lave \& E. Wenger, Situated learning: Legitimate peripheral participation. Cambridge, UK: Cambridge University Press. 1991.

[56] Patrick Lavoie, Cécile Michaud, Marilou Bélisle, et al. "Learning theories and tools for the assessment of core nursing competencies in simulation: A theoretical review," J. Adv. Nurs.; 74:239-250, 2018.

[57] Stéphane Lhuillery Julio Raffo, and Intan Hamdan-Livramento, Economic Research Working Paper No. 31, Measuring Creativity: Learning from Innovation Measurement, World Intellectual Property Organization, Geneva, 2016.

[58] Saundra Y. McGuire and Stephanie McGuire, Teach Students How to Learn, Stylus Publishing, 2015.

[59] Thomas A. O'Neill, Amanda Deacon, Nicole L. Larson, Genevieve C. Hoffart, Robert W. Brennan, Marjan Eggermont, William Rosehart, "Life-long learning, conscientious disposition, and longitudinal measures of academic engagement in engineering design teamwork," Learning and Indiv. Diff., 39(2015), 124-131, Elsevier, 2015.

[60] P.R. Pintrich, "The role of goal orientation in self-regulated learning" in M. Boekaerts, P. Pintrich, \& M. Zeidner (Eds.), Handbook of selfregulation p. 451-502. San Diego, CA: Academic, 2000.

[61] Aneeta Rattan, Catherine Good, and Carol S. Dweck. "It's Ok Not Everyone Can Be Good at Math': Instructors with an Entity Theory Comfort (and Demotivate) Students." Journal of Experimental Social Psychology 48, no. 3 (May 2012): 731-37.

[62] L. Resnick, \& L. Klopfer, (Eds.) Toward the Thinking Curriculum: Current Cognitive Research, 1989. Alexandria, VA: Association for Supervision and Curriculum Development.

[63] S. Sarasvathy \& S. Venkataraman, "What Makes Entrepreneurs Entrepreneurial?" www.effectuation.org 2001.

[64] S. Sarasvathy, \& S. Venkataraman, "Entrepreneurship as Method: Open Questions for an Entrepreneurial Future," Entrepreneurship Theory and Practice. 35, No. 1: p. 113-135.

[65] Donald Schon, Educating the reflective practitioner Towards a new design for teaching and learning in the professions. San Francisco: Jossey-Bass, 1987.

[66] Donald Schon, The reflective practitioner: How professionals think in action. England: Arena, 1995.

[67] Dale A. Schunk "Learning theories an educational Perspective," $6^{\text {th }}$ ed, Pearson: Boston, MA, 2012.

[68] Gordon Stubley, "Thinking about learning - inferences from how we support curriculum design," in Proc. (CEEA18), Paper 38, 2018.

[69] Norman D. Vaughan, "A blended community of inquiry approach: Linking student engagement and course redesign," The Internet and Higher Education, vol. 13, no. 1, pp. 60-65, 2010.

[70] E. Wenger, R. McDermott, and W.M. Snyder, "Cultivating Communities of Practice” Boston: Harvard Bus. School Press, 2002.

[71] Barry J. Zimmerman \& Dale H. Schunk, "Albert Bandura: The scholar and his contributions to educational psychology," In B. J. Zimmerman \& D. H. Schunk (Eds.), Educational psychology: A century of contributions (pp. 431-457). Mahwah, NJ: Erlbaum. 


\section{Appendix A: Key Framework Relationships}
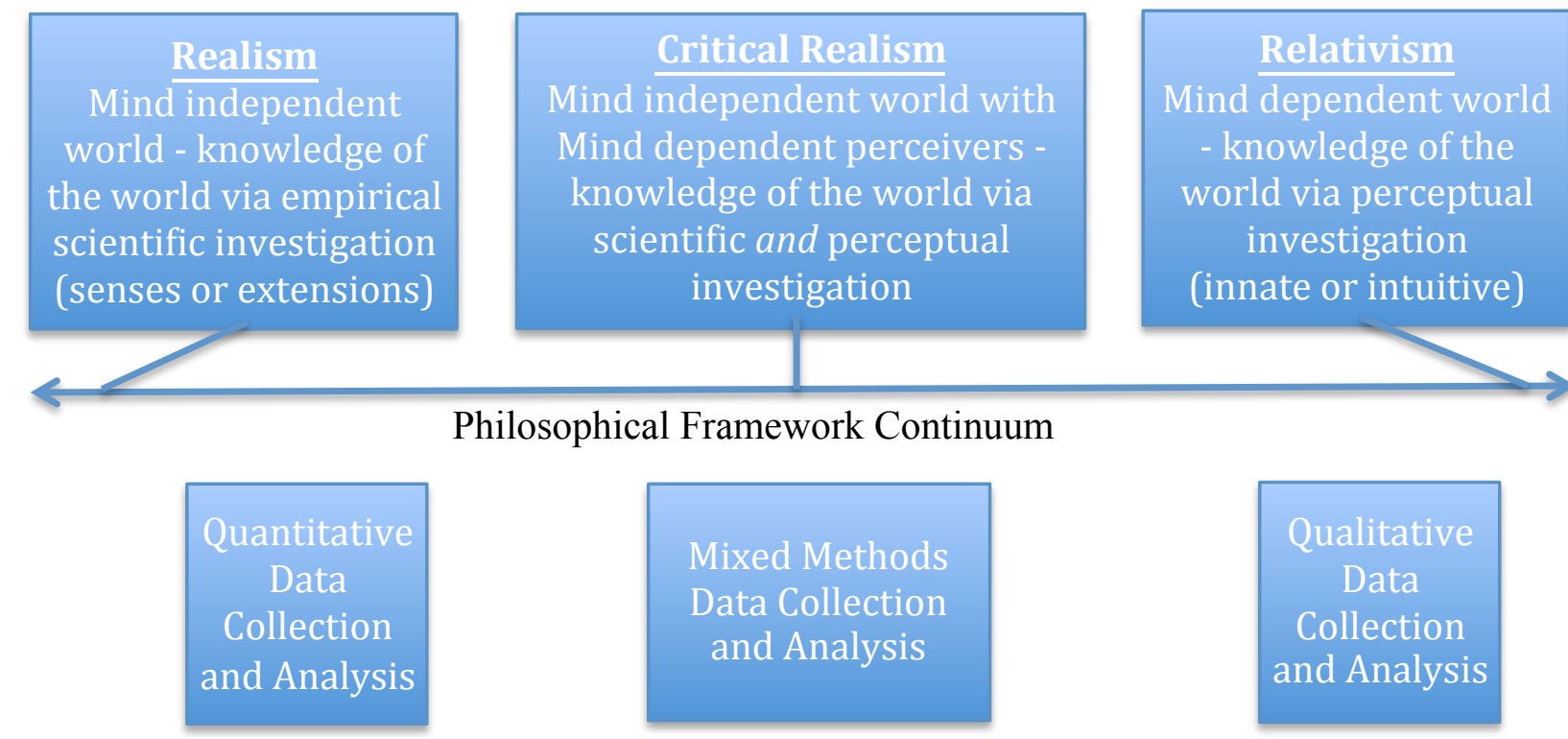

Philosophical Framework Continuum

Data Collection and Analysis Methods Epistemological Orientation

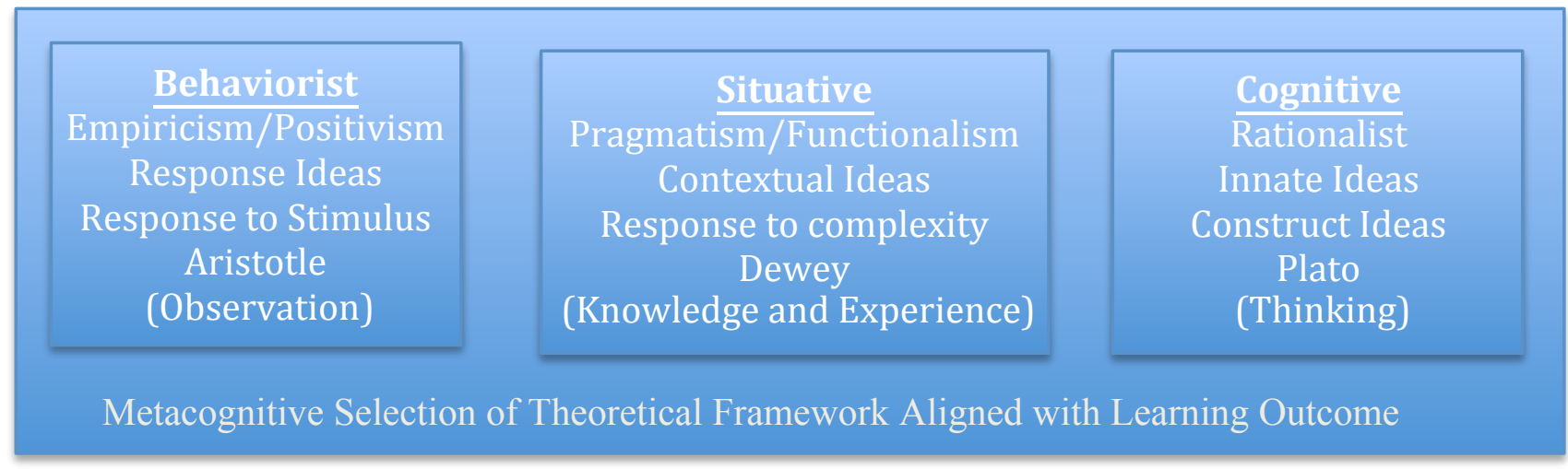

Key Learning Theoretical Frameworks with Underlying Philosophical Frameworks
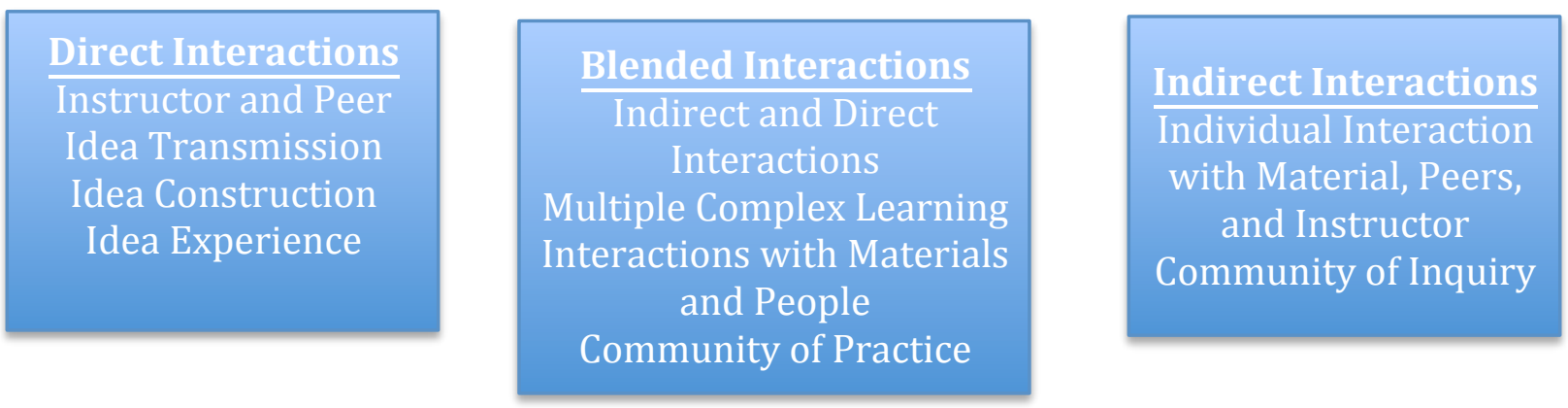

Combined Metacognitive Course and Program Delivery Frameworks Social, teaching, and cognitive presences and using all learning frameworks 


\section{Appendix B: Conceptual Framework Analysis Process (Condensed version)}

The methodology is composed of the following key steps as outlined by Yosef Jabareen, 2009.

\section{Step 1: Mapping the selected data sources}

"This process includes identifying text types and other sources of data, such as existing empirical data and practices... it is also recommended to undertake initial interviews with practitioners, specialists, and scholars from various disciplines whose work focuses on the targeted phenomenon." (Jabareen, 2009, p.53)

\section{Step 2: Extensive reading and categorizing of the selected data}

"The aim in this phase is to read the selected data and categorize it...This process maximizes the effectiveness of our inquiry and ensures effective representation..." (Jabareen, 2009, p.54)

\section{Step 3: Identifying and naming concepts}

"The aim in this phase is to read and reread the selected data and "discover" concepts (Glaser \& Strauss. 1967; Strauss \& Corbin. 1990). Its result is a list of numerous competing and sometimes contradictory concepts. Generally, this method allows concepts to emerge from the literature." (Jabareen, 2009, p.54)

\section{Step 4: Deconstructing and categorizing the concepts}

"The aim of this phase is to deconstruct each concept; to identify its main attributes, characteristics, assumptions, and role; and, subsequently, to organize and categorize the concepts according to their features and ontological, epistemological, and methodological role. The result of this phase is a table that includes four columns. The first includes the names of the concepts; the second includes a description of each concept; the third categorizes each concept according to its ontological, epistemological, or methodological role; and the fourth presents the references for each concept." (Jabareen, 2009, p.54)

\section{Step 5: Integrating concepts}

"The aim in this phase is to integrate and group together concepts that have similarities to one new concept. This phase reduces the number of concepts drastically and allows us to manipulate to a reasonable number of concepts." (Jabareen, 2009, p.54)

\section{Step 6: Synthesis, resynthesis, and making it all make sense}

"The aim in this phase is to synthesize concepts into a theoretical framework. The researcher must be open, tolerant, and flexible with the theorization process and the emerging new theory. This process is iterative and includes repetitive synthesis... until the researcher recognizes a general theoretical framework that makes sense." (Jabareen, 2009, p.54)

\section{Step 7: Validating the conceptual framework}

"The aim in this phase is to validate the conceptual framework. The question is whether the proposed framework and its concepts make sense not only to the researcher but also to other scholars and practitioners. Does the framework present a reasonable theory for scholars studying the phenomenon from different disciplines? Validating a theoretical framework is a process that starts with the researcher, who then seeks validation among "outsiders." Presenting an evolving theory at a conference, a seminar, or some other type of academic framework provides an excellent opportunity for researchers to discuss and receive feedback." (Jabareen, 2009, p.54)

\section{Phase 8: Rethinking the conceptual framework}

"A theory or a theoretical framework representing a multidisciplinary phenomenon will always be dynamic and may be revised according to new insights, comments, literature, and so on. As the framework is multidisciplinary, the theory should make sense for those disciplines and enlarge their theoretical perspective on the specific phenomenon in question." (Jabareen, 2009, p.55) 


\section{Appendix C: Canadian Engineering Accreditation Board Graduate Attributes}

Coding Legend: behaviour response cognitive response situative contextual response

1. A knowledge base for engineering: Demonstrated competence in university level mathematics, natural sciences, engineering fundamentals, and specialized engineering knowledge appropriate to the program.

2. Problem analysis: An ability to use appropriate knowledge and skills to identify, formulate, analyze, and solve complex engineering problems in order to reach substantiated conclusions.

3. Investigation: An ability to conduct investigations of complex problems by methods that include appropriate experiments, analysis and interpretation of data, and synthesis of information in order to reach valid conclusions.

4. Design: An ability to design solutions for complex, open-ended engineering problems and to design systems, components or processes that meet specified needs with appropriate attention to health and safety risks, applicable standards, and economic, environmental, cultural and societal considerations.

5. Use of engineering tools: An ability to create, select, apply, adapt, and extend appropriate techniques, resources, and modern engineering tools to a range of engineering activities, from simple to complex, with an understanding of the associated limitations.

6. Individual and teamwork: An ability to work effectively as a member and leader in teams, preferably in a multi-disciplinary setting.

7. Communication skills: An ability to communicate complex engineering concepts within the profession and with society at large. Such ability includes reading, writing, speaking and listening, and the ability to comprehend and write effective reports and design documentation, and to give and effectively respond to clear instructions.

8. Professionalism: An understanding of the roles and responsibilities of the professional engineer in society, especially the primary role of protection of the public and the public interest.

9. Impact of engineering on society and the environment: An ability to analyze social and environmental aspects of engineering activities. Such ability includes an understanding of the interactions that engineering has with the economic, social, health, safety, legal, and cultural aspects of society, the uncertainties in the prediction of such interactions; and the concepts of sustainable design and development and environmental stewardship.

10. Ethics and equity: An ability to apply professional ethics, accountability, and equity.

11. Economics and project management: An ability to appropriately incorporate economics and business practices including project, risk, and change management into the practice of engineering and to understand their limitations.

12. Life-long learning: An ability to identify and to address their own educational needs in a changing world in ways sufficient to maintain their competence and to allow them to contribute to the advancement of knowledge 